\title{
ANALYSIS THE ADVANCED ICT USAGE OF THE HUNGARIAN SME SECTOR FOR PREPARING A DOMESTIC AGRI-FOOD RESEARCH
}

\author{
Szilvia Botos ${ }^{1}$ - János Felföldi ${ }^{2}$ - László Várallyai ${ }^{3}$ - Ádám Péntek ${ }^{4}$ - Róbert Szilágyi ${ }^{5}$ \\ University of Debrecen, Faculty of Economics and Business, \\ Institute of Applied Informatics and Logistics, H-4032 Debrecen, Böszörményi Str. 138. \\ ${ }^{1}$ botos.szilvia@econ.unideb.hu \\ 2 felfoldi.janos@econ.unideb.hu \\ 3varallyai.laszlo@econ.unideb.hu \\ ${ }^{4}$ pentek.adam@econ.unideb.hu \\ ${ }^{5}$ szilagyi.robert@econ.unideb.hu
}

\begin{abstract}
In the Hungarian agro-food sector SMEs have a key role but regarding the tendency of the performance of SME sector, comparing to EU-28 average, the performance of Hungarian SME sector has gradually worsened between 2008 and 2015 while the EU average has an increasing trend. ICT can help enterprises and this article is an overview of the ICT situation of Hungarian SMEs. It is important to analyse in detail the ICT usage characteristics of agro SMEs in the food supply chain because these ICT devices, tools and services are crucial to smooth the information flow within the chain. For all these reasons our work aims to find out how Hungarian agro-food SMEs use ICT and how ICT adoption affect their business procedures, performance and development. A striking observation to emerge from the data comparison is the difference among SMEs and large enterprises regarding the usage of the different basic and advanced ICT solutions. A much bigger percent of large companies use advanced ICT then SMEs and mainly small enterprises are lagging behind as the attitudes of medium sized enterprises are rather similar to the large ones. In Hungary small enterprises in agro-food industry are in difficult financial state and for them free Cloud Computing services can offer good opportunities as they do not have initial costs. ICT adoption is very important to them as ICT sector is a dynamically growing sector and if customers and partners of an enterprise adapt faster to these technological innovations, it may have a negative effect on the different processes, performance and financial results of the organisation. In this article our aim was to determine the main question groups for our questionnaire which focus mainly on ICT solutions supporting the quality of communication and relationship between partners. As the basic IT tools are available in the major part even in the SMEs besides large companies, the two main issues will be the usage of advanced online services and the usage of high quality ICT solutions.
\end{abstract}

Keywords: small and medium sized enterprises, agro-food, information and communications technology.

(JEL Code: M15)

\section{INTRODUCTION}

Agriculture and food industry have a specific role in the Hungarian economy. Soil is one of the main natural resources and environmental circumstances (e.g. soil quality, climatic conditions, and water supply) are more than favourable for agricultural production. All the natural conditions for creating a strong and developing agro-food sector are in place supported by a deeply rooted tradition of cultivating arable corps, vegetable and fruit, breeding animal and producing high quality food. But the role of agro-food sector has been decreasing for decades because of the adverse economic environment surrounding the enterprises operating in these sectors and their international position is weak as well. The situation of agro-food SMEs is particularly unstable and vulnerable as they suffer severe economic disadvantages (e.g. productivity, bargaining power, partnerships or the volume of marketable production) compared to the large companies cultivating agricultural crops and other plants or producing food, causing negative effects on social and economic development. Because of this, we need to find tools helping the agro-food SMEs (Small and Medium sized enterprises) to be profitable despite the difficult economic environment, to start growing, to strengthen their competitive position and to exploit their capacities. As many processes in the world, different economic sectors also moving towards integration so enterprises in agro-food industry also require a supply chain level approach, connecting to other players of the chain. 
In the light of the above, our Institute decided to analyse the Information and Communication Technology (ICT) characteristics of SMEs operating in the Hungarian agro-food sector and we compiled a questionnaire in order to collect data on it. The information gained from the survey are important as statistical databases publicly available provide limited data on restricted queries like different ICT usage indicators of enterprises operating in food industry. On the other hand, the analysis of different ICT indicators available for SME sector in national and international statistical databases served as an aid in determining the main sets of questions for our questionnaire. On the basis of this analysis we could design our questionnaire specifically for analysing the ICT situation of Hungarian agro-food SMEs. The focus group of our questionnaire analysing the food manufacturing part of the chain will be the meat, milk and fruit and vegetable processing and manufacturing SMEs.

Our aim in current article is to identify and present the determinant hampering and motivating factors in ICT acceptance and in this way to give a comprehensive picture of ICT usage characteristics of Hungarian SMEs in general. The first section of this article gives a brief overview about the agro-food supply chain in general and the importance of ICT in SME development. In order to identify how and to what extent ICT tools could help information flow in the chosen part of the food supply chain we first collected data on ICT usage and the second section contains our analysis on them and presents the main ICT features of the Hungarian SMEs based on publicly available statistical data. Our results are drawn in the final section.

There are several aspects to analyse the food supply chain depending on which part of the chain is studied. There are three main actors in the chain: the agriculture, the processing sector of food and drink and the distribution and retail sector. On Figure 1 the parts and actors of food supply chain can be seen with the major flows among the actors.

Together, the agricultural sector, the food and drink industry (processing and manufacturing) and the distribution sector (wholesale and retail) are the driving forces of the food supply chain but there is no single, homogeneous, and common food supply chain at European level. The length and the degree of complexity of food supply chains depend on the product and market characteristics (EUROPEA N COM M ISSION, 2015).

A s regards the different parts of food supply chain we can talk about two major types of industries: the food and drink industry and the agro-food industry. The food and drink industry includes all the processed products values and the retail sector. The agro-food industry is centred on making, processing, preparing and packaging food products for human consumption. Its raw materials come from the primary sector, specifically from agriculture (BARCELONA TREBALL, 2013).

First of all, specifying the focus area within the whole supply chain is crucial. The priority topic of our Institute's research is the ICT characteristics of SM Es operating in the agro-food part of the chain. We have chosen this topic, because:

ICT can boost the different business activities and there are many studies, articles and papers on the positive direct and indirect impacts of ICT to business processes and production,

the most business players belongs the agro-food part of the chain in Hungary, the companies belonging to the other part of the chain mainly have foreign interest and management,

SMEs have an essential role in the Hungarian economy.

In our previous paper (FELFÖLDI et al. 2017) we analysed the agricultural enterprises. In this article we continue with a general ICT analysis of Hungarian SMEs which also means an indication for determining the main sets of questions for our subsequent survey.

Encouraging higher uptake of ICT is essential for the SME sector also as the competitiveness of SMEs are able to develop using ICT adoption in order to increase business transformation, information exchange efficiency and effectively (KUSUMANINGTYAS and SUWARTO 2015; RAHMANA, 2009). One of the findings of the article of Martin et al, 2013 is the ICT devices and the different information systems enable enterprises and also staff to be more productive in the use of information from the different business processes. ASSANTE et al. (2016) also offers many opportunities and could help companies to improve their business and use technology more efficiently. For example EDI which does not necessarily increase sales, its use can reduce operating costs as computer to computer exchange is

Figure 1. The general linear structure and parts of Food Supply Chain

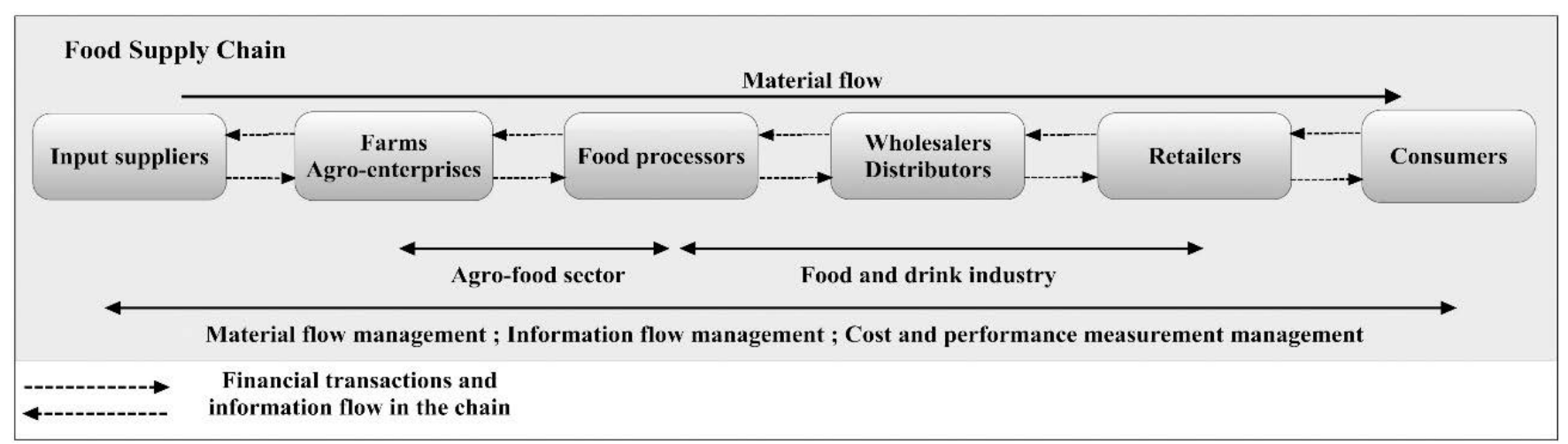

Source: Own editing on PULLMANN and WU 2012; BERTI and MULLIGAN 2015 
much less expensive than traditional methods of document exchange. The use of EDI can also speed up and reduce errors in information sharing (FÜZESI et al. 2016b). One of the objectives of the work of GÁL et al. (2013) also was to elaborate a decision-support system as over the past years the profitability and competitiveness of the Hungarian bovine sector has been declining, so it is of high priority to ensure tools for decision-makers that makes farming more efficient. In their article summarizing a vast amount of literature on this research field, TARUTÉ and GATAUTIS (2014) found that technology itself is not as important as the induced social and economic achievements thus in the case of the indicators chosen the evaluation of how ICT affect economic processes is important and ask only just for those. To create business process management systems using mobile or cloud technologies could allow supply chains and the stakeholders to break through in today's industry because of their significantly lower entry cost (BERTI and MULLIGAN 2015), but SME sector means a bottleneck in use of ICT tools for decades besides the households, mainly in rural regions (PIERSON, 2005; STRUZAK, 2010; OECD, 2015). One of the principal weaknesses of Hungarian SMEs is the low innovation ability as well (including ICT usage) and performance (SZIRA, 2014).

The main problem is the low diffusion of ICT as ICT adoption is a complex process (KUSUMANINGTYAS and SUWARTO 2015) for a number of reasons and a key challenge for ICT in the agriculture sector is information management, both within specific domains and across the whole supply chain from farm to fork (BREWSTER et al. 2012). Another challenge to be faced is the general lack of a long-term strategic vision of SMEs as using ICT can bring benefits only after a period of adoption although the length of this period is influenced by several factors and one of them is the quality of internal and external interactions (CONSOLI, 2012). TARUTÉ and GATAUTIS (2014) also highlighted that marketing, external and internal communication, networking and resource planning are the key areas that ICT impacts the most. This problem can be observed also in enterprises operating Hungarian meat sector. With respect to the present income relations of the branch, the investment recovery time is too long (FÜZESI, 2016a). The amount spent on the IT systems of the sector in 2009 was approximately $0.6 \%$ of the revenue, which changed to $0.7 \%$ by 2016 . The rate is extremely low, it must be emphasized that IT investments should be increased to increase the competitiveness of the sector (FÜZESI, 2016a).

In the case of inbound and outbound logistics where the communication with suppliers would be cheaper and faster through supply chain management or the usage of e-commerce, e-marketing and CRM techniques also could improve the performance of marketing and sales activities. Most SMEs across the world are increasingly adopting various ICTs to enhance their e-readiness status to identify, acquire, organise, disseminate and apply information for informed decision making (ONGORI and MIGIRO 2010), but according to RAMÍREZ-MEDINA (2009) more company consider important and innovative the usage of e-technologies than are introduced. Even so, despite the difficulties, a relatively dynamic increase was observed in the usage of advanced ICT solutions in agro-food enterprises as well. For instance in the Hungarian meat sector there was a $22 \%$ increase from $28 \%$ (2009) to 50\% (2016) in the rate of enterprises using integrated systems which is a result of the availability of funding resources for introducing ERP systems on the one hand and the partner expectations on the other hand (FÜZESI, 2016a).

Partner expectations also had an effect on the use of EDI as it has mainly concentrated on larger companies, but only because of pressure from their business partners or competitors, smaller companies often started to use EDI. Other recent surveys also found agro-food SMEs are getting interested in practical, close to market applications and they started to recognize the advantages of using the Cloud. For instance, SASVÁRI (2016) made a comparison on Cloud Computing usage between Austrian and Hungarian enterprises and the results suggest that SMEs consider the high-level mobility and remote access to information systems while large enterprises the faster information flows as advantages.

TARUTÉ and GATAUTIS (2014) mentioned in their article the study of MATTHEWS (2007) that identified three distinct stages (basic, substantial and sophisticated) in ICT use in small businesses. This classification was useful in the preparation work of our questionnaire because these three stages are true for today's companies and in order to design our questionnaire elements we had to divide the statistical indicators into these three classes. For this, we overviewed several publications on the impact of ICT on SMEs performance and classified the different ICT indicators into the above mentioned classes. Furthermore, according to GUO and JIN (2009) the usage of basic ICT and e-commerce just helps survival, it does not mean economic advantage for the enterprises in a market where there is high degree of competition. If rural SMEs want to be competitive now, they need to extra services which increase the satisfaction of partners and customers and the safety of business transactions. The article reviewing a high number of publications of CONSOLI (2012) summarizes well the determinant factors of ICT usage and impacts of ICT on SMEs and highlighted that the analysis of these factors is very important to understand how to stimulate SMEs to invest in new ICTs to acquire competitive advantages and good business performance. KALOXYLOS et al. (2013) deal with the influence of different Internet-based services in their article and they have presented the SmartAgrifood architecture that aims at building an integrated food chain that will allow data to be transferred bi-directionally in an automatic and simple way. It is important, because as POPPE et al. (2013) explain, by improving the interoperability of data which are being generated in agriculture and the rest of the food chain, the processes can be optimized and data-intensive food chains have the potential to alleviate many of the current sustainability and food safety issues.

Agro-food enterprises operate in a complex and dynamic 
environment and to meet increasing demands of consumers, government and business partners, enterprises continuously have to work on innovations of products, processes and ways of cooperation in agro-food supply chain networks (WOLFERT et al. 2010). Innovations in different processes can make products more suitable for global distribution, and innovations in management and ICT allows supply chains to become more responsive to the increasingly sophisticated food demands of consumers (DANI, 2015). In the case of agro-food SMEs relevant and reliable information is needed regarding the ingredients of a product and the production processes so that companies may recall their products in case of a food safety problem (FÜZESI et al. 2016a). However, those ICT tools which used for tracing the products - and which must be used in many cases in accordance with food safety legislations - not only provide information for food safety but for management and these information could be vital for smooth the material flows and for maintain continuity of information flows which could increase the efficiency and reduce costs.

In summary, it is important to analyse in detail the ICT usage characteristics of agro SMEs in the food supply chain because these ICT devices, tools and services are crucial to smooth the information flow within the chain. For all these reasons our future work aims to find out how Hungarian agro-food SMEs use ICT and how ICT adoption affect their business procedures, performance and development.

\section{MATERIALS AND METHODS}

The used data set in current article derived from the database of Eurostat. Descriptive statistics were made in order to obtain a comprehensive picture on ICT characteristics of Hungarian SME sector and to determine their situation among the EU-28 Member States. The data presented are percentages and all graphs the unit is percentage of all enterprises in all cases. Standard deviation was calculated for each indicator to determine the distribution of the values of the different countries and the results showed normal distribution. On the basis of SD we can say there were not significant differences among the Member States. The differences were higher in the case of basic ICT indicators and lower in the case of the advanced ICT indicators which means that enterprises did not reach a high usage percentage even in well performing countries regarding ICT readiness. To exclude outliers we used frequency and the results showed there was only one outlier. For calculating frequency we divided the ranges into quartiles and the number of items were adequate (5-10) in the case of all indicators in the bin ranges with one exception. Finland was excluded from the analysis in the case of the 'Integration with partners' indicator. We thus presented the indicators as bin ranges containing the values of all Member States between the minimum and maximum values and highlighted the values of Hungary.

\section{RESULTS AND DISCUSSION}

The agro-food industry - the first part of the chain - is the second largest segment of the EU: more than 12 million farms produce agricultural products for processing by about 290,000 enterprises in the food and drink industry (EUROPEAN COMMISSION, 2015b). Agro-food industry has a major importance in the Hungarian economy as well. In Hungary, $62.9 \%$ of the overall territory (9.3 million hectares) are utilized for agricultural activities. Eighty per cent of the total territory of Hungary is agricultural production area and more than half $(59 \%)$ of this area is arable land. Almost 1 million farmers work in this sector and there are over 5,000 registered food businesses in the country. The expenditure for food and non-alcoholic beverages from the total annual living expenditure (per capita) is $23.1 \%$ in Hungary (HCSO, 2014; FLANDERS, 2015). Agro-food processing industry means higher added value and thus it contributes to the GDP in higher proportion than the simple production of primer agricultural products. The sector has a key importance even in compared to the other EU-members' food industry, so keeping and developing the competitive advantage is crucial.

SME sector is also especially important to the overall

Hungarian economy as they mean approximately $99 \%$

from the total operating enterprises, it provides jobs for $73.8 \%$ of the employees in business sector and they produce about $50 \%$ of the Gross Value Added (HCSO, 2015). In

the Hungarian agro-food sector SMEs also have a key role. $98 \%$ of the agricultural holdings are SMEs - however they only use $36 \%$ of the agricultural land. They represent almost the half of the total amount of agricultural standard output and $84 \%$ of agricultural employees are directly employed by small and medium sized holdings. The features of SMEs operating in food and drink industry is

Figure 3. The change of performance of Hungarian SMEs compared to EU-28 between 2008 and 2015

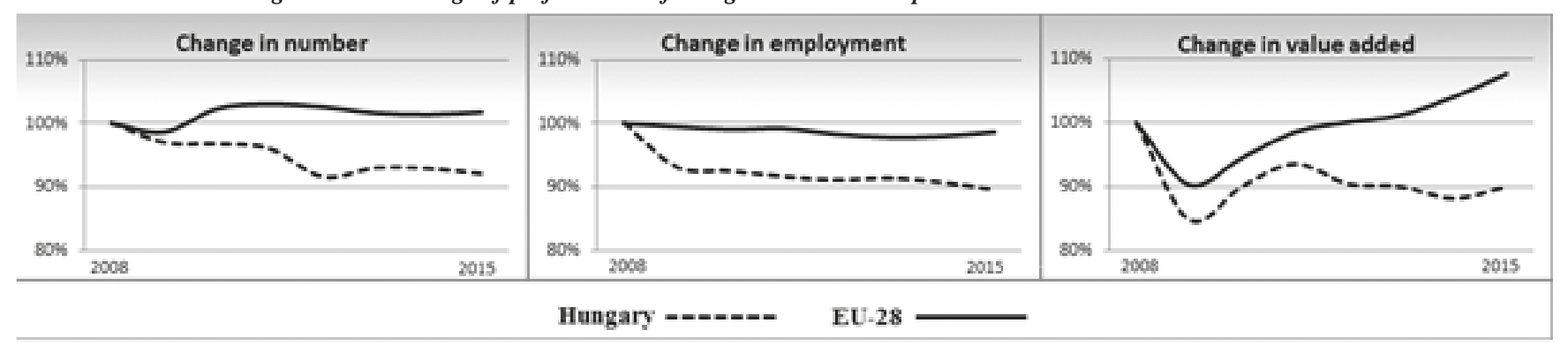

Source: HCSO, 2016 
similar to the agricultural contribution structure. According to Hungarian Statistical Agency, in 2015 the number of agro-food enterprises (including agriculture, forestry and fishing and manufacturing of food products, beverages and tobacco products) was almost $5 \%$ of the total number of enterprises operating in the Hungarian economy (HCSO, 2015). The characteristics of SMEs in the Hungarian food and drink industry is shown on Figure 2.

Figure 2. Contribution of enterprises to the food and beverages industry by size in Hungary, 2015

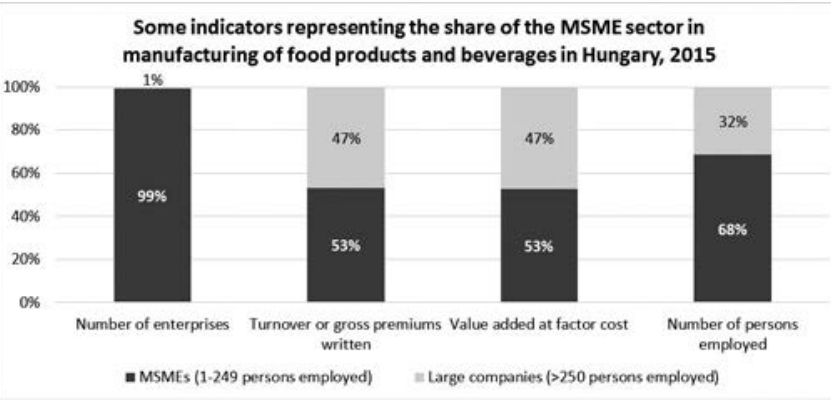

Data source: EUROSTAT, 2017

Regarding the tendency of performance of the SM E sector, comparing to EU -28 average, the performance of Hungarian SM E sector has gradually worsened between 2008 and 2015 as shown on Figure 3.

We can see that the performance of Hungary is on the wane while the EU average has an increasing trend. ICT can help enterprises and this article is an overview of the ICT situation of Hungarian SM Es. A s we discussed in the literature review, we analysed mainly the online presence and the usage of basic and advanced onl ine services of SM Es and large enterprises. Figure 4. reports the online presence of enterprises of the $E U$ M ember States by size in 2016 by three different indicators shown separately the values of small, medium and large enterprises. The difference between the best and the worst country can be seen on the range lines highlighting the data of Hungary.

Figure 4. Online presence of small, medium and large enterprises of EU Member States in 2016 (in percentage of enterprises)

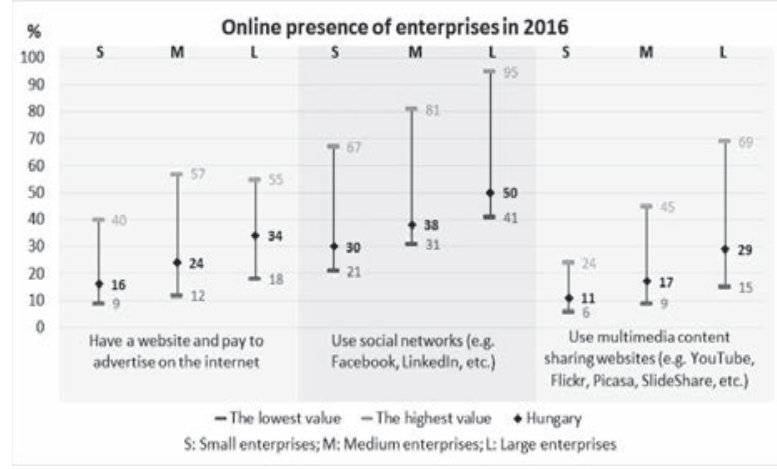

Data source: EUROSTAT, 2016
It is apparent from graph above that there is significant difference in three senses: among the different forms of online presence, among M ember States and among enterprises of different sizes. There is no significant difference among medium and large enterprises in the first indicator but the usage rate is not satisfactory as around half of the enterprises had a website and paid to advertise on the internet in 2016, however, this is one of the most important and the most efficient marketing opportunity today. Small enterprises are lagging behind the larger companies by 15 per cent. A striking observation to emerge from the data comparison is the difference among SM Es and large enterprises regarding the usage of social networks or multimedia content sharing websites. The usage rate of the latter is relatively low in the case of small enterprises, but medium sized and large companies are performing well as this opportunity is an advanced ICT tool while having a website or advertising online count basic tools but the range and the proportion of enterprises using this tool is similar to the first indicator.

In order to determine the situation of Hungary among EU M ember States we divided the data set into quartiles and Hungary was in the lower quartile of all EU Member States with its 2016 usage values in al most all cases. Hungary, however, was in the mid-range in terms of the first indicator, but in the case of the latter two indicators it was among the last and ranked ahead only Romania, Bulgaria and Slovakia and besides these Lithuania and Czech Republic in terms of the third indicator. Scandinavian countries top the rank in each cases with Denmark, Sweden and Netherlands and in some cases Estonia also belongs to the leader group. It is remarkable that $M$ al ta has the highest values in the case of the first indicator, but in terms of the other two indicators, we can say $M$ alta performs above the EU average.

In terms of why enterprises use social media there are considerably differences and Figure 5 demonstrates well the usage rate of social media for basic and advanced purposes. The first two aim are mainly focus on marketing appearance and customer relationship management, while the last two aim at involving other partners of the chain (customers, business partners and other organisations) into their business procedures and creating opportunity for innovation.

A lthough the usage rate of social media is high, there are considerable differences regarding the purposes. The graph below shows large enterprises use social media for multiple purposes including advanced ones than the small enterprises using it mainly for marketing purposes. It is worthwhile noting that in the case of the latter two purposes the usage rate is weak even in the case of large enterprises. 
Figure 5. Social media use of small, medium and large enterprises of EU Member States in 2016 by purpose (in percentage of enterprises)

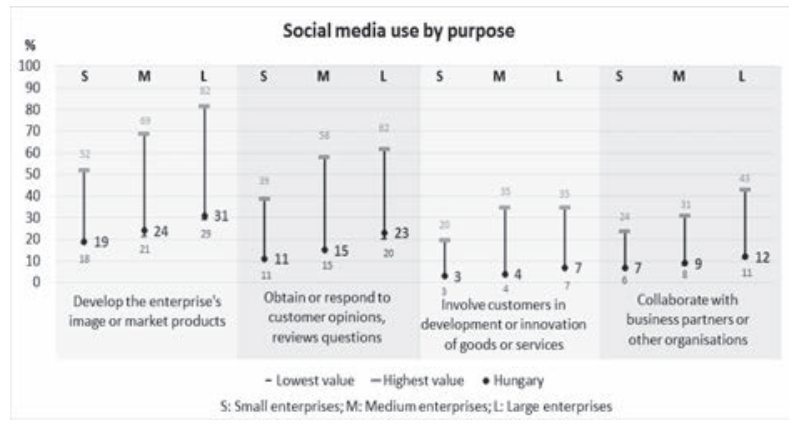

Data source: EUROSTAT, 2016

Regarding the values of the four indicators appreciable differences were found not only between SM Es and large enterprises but between the first two and the last two indicators. While in the first two cases both the range and the highest values are higher, the last two indicators show a smaller range and the highest values are low and less than half of the enterprises use social media to involve customers in development of innovation of goods or services or collaborate with business partners or other organisations. This result indicates, for supply chain, that enterprises use social media for marketing purposes mainly for communication with customers. With business partners or other organisations they do not use these opportunities and apart from sales customers are not involved in other business processes such as innovation of goods or services. The graph also shows small companies are very behind, medium sized enterprises have si milar characteristics than large companies, the gap between them is small.

The next two indicators reflecting integration of enterprises (sending and receiving elnvoices suitable for automated processing) presented on Figure 6.

Figure 6. Integration with partners of small, medium and large enterprises of EU Member States in 2016 (in percentage of enterprises)

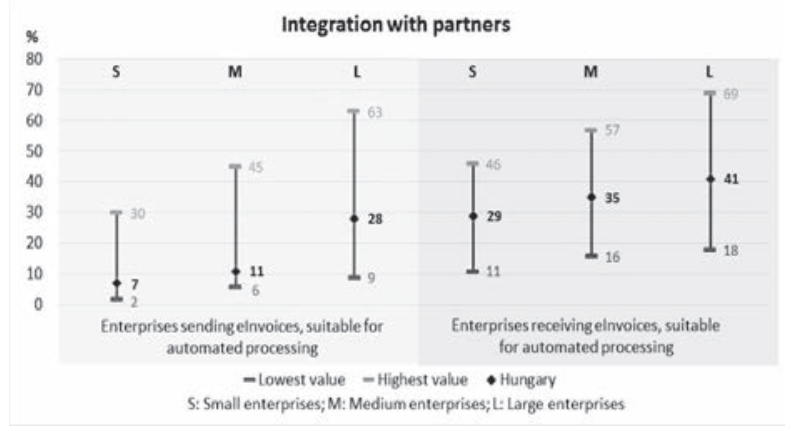

Data source: EUROSTAT, 2016

Finland was not included in the analysis because of its outliers and in the case of the first indicator Denmark and Slovenia either. The lowest percentage of enterprises use el nvoices are mainly Southern European countries but the United Kingdom and Luxembourg are also belongs to this group. Regarding Hungary, large companies have relatively high position in the two indicators and a high proportion of medium-sized companies receive el nvoices. Concerning the first indicator, SMEs have very low values, 7 and 11 per cent of the enterprises send el nvoices to their partners.

The situation of Hungarian SM Es regarding to the use of Cloud services is far under the average of EU-28 and its level is shown on Figure 7 .

Figure 7. Use of pay Cloud Computing services of small, medium and large enterprises of $\mathrm{EU}$ Member States in 2016

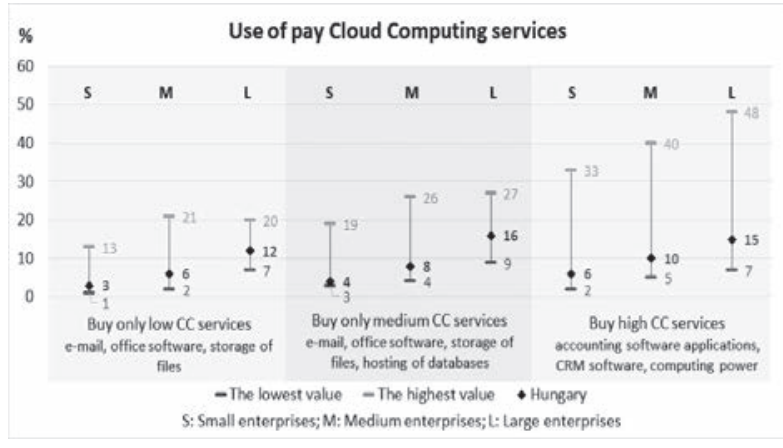

Data source: EUROSTAT, 2016

Our position is very poor even the average usage ratio is low in other Member States as well in the case of the first two indicators. Only a few percentage (3-16\%) of Hungarian SM Es buy cloud computing services over the internet and with this result Hungary is in the lowest quartiles in this term as well.

In this article our aim was to determine the main question groups for our questionnaire which focus mainly on ICT solutions supporting the quality of communication and relationship between partners. As the basic IT tools are available in the major part even in the SM Es besides large companies, the two main issues will be the usage of advanced online services and the usage of high quality ICT solutions. Thus the following question groups are planned to be in the questionnaire:

- Use of social media and its purposes

- Use of free and pay Cloud Computing services

- ICT solutions supporting integration with partners

ICT situation of agro-food SMEs is difficult to determine from public databases. Thus we used general statistics to create question groups and questions for our questionnai re in order to understand ICT situation targeted taking into account the comparability. We focus on sector specific questions taking into account the characteristics of the Hungarian agro-food SM Es to be involved into the survey and pay particular attention to solutions suitable to help them such as open source software and applications or free Cloud services. By understanding the level and features of usage of these ICT tools help us to determine the related issues as the different hampering or motivating factors or the economic impacts.

Statistical analysis show well there are significant differences in some cases among enterprises of different 
sizes. A much bigger percent of large companies use advanced ICT solutions then SMES and mainly small enterprises are lagging behind as the attitudes of medium sized enterprises are similar to the large ones. In Hungary small enterprises in agro-food industry are in difficult financial state and for them free Cloud Computing services can offer good opportunities as they do not have initial costs. ICT adoption is very important to them as ICT sector is a dynamically growing sector and if customers and partners of an enterprise adapt faster to these technological innovations, it may have a negative effect on the different processes, performance and financial results of the organisation. Our institute set the detailed analysis of the food chain as an objective and in the frame of this work we will evaluate the usage rate of the advanced ICT solutions, the motivating and hampering factors of SM Es operating in agro-food sector.

\section{REFERENCES}

Assante D, Castro M, Hamburg I, Martin S. (2016): The Use of Cloud Computing in SMEs. Procedia Computer Science, Vol 83. pp. 12071212.

Barcelona Treball. (2013): Agro-Food Industry - Sector Report 2013. Available at: http://w27.bcn.cat/porta22/images/en/Barcelona treball Informe_sectorial_Agro_food_industry_gen2013_en_tcm43-4016.pd $\bar{f}$

Berti G, Mulligan C. (2015): ICT \& the Future of Food and Agriculture. Industry Transformation - Horizon Scan: ICT \& the Future of Food. Telefonaktiebolaget LM Ericsson, Stockholm, Sweden.

Brewster C, Wolfert S, Sundmaeker H. (2012): Identifying the ICT challenges of the Agri-Food sector to define the Architectural Requirements for a Future Internet Core Platform. Proceedings eChallenges e-2012, Lisbon, Portugal. pp. 1-8.

Consoli D. (2012): Literature analysis on determinant factors and the impact of ICT in SMEs. Procedia - Social and Behavioral Sciences, Vol 62 pp. 93-97.

Dani S. (2015): Food Supply Chain Management and Logistics - From Farm to Fork. Kogan Page, London, Philadelphia, New Delhi.

European Commission. (2015): Background on the EU food supply chain: an important economic sector.

Available at: http://ec.europa.eu/competition/sectors/agriculture/overview_en.html

Eurostat databases

Felföldi J, Botos Sz, Péntek Á, Szilágyi R, Várallyai L. (2017): Studying the ICT management of agri-food sector on supply chain level - the first stage: analysis of agricultural ICT usage. In: Anastasios Karasavvoglou, Persefoni Polychronidou (editors) Agricultural Sector Issues in the European Periphery: Productivity, Export and Development Challenges. Wilmington: Vernon Press, 2017. pp. 35-50.

Flanders Investment \& Trade. (2015): Agro \& Food Sector in Hungary. Flanders Investment \& Trade, Budapest, Hungary.

Füzesi I, Lengyel P, Csobán K, Szilágyi R. (2016a): Analysis of ICT Support in Hungarian Meat Sector. Agrárinformatika / Journal of Agricultural Informatics, Vol. 72 pp. 60-69.

Füzesi I, Lengyel P, Szilágyi R, Ráthonyi G. (2016b): Application of EDI Technologies in the Food Supply Chains. Journal of EcoAgriTourism, Vol. 121 Iss 32 pp. 69-77.
Gál T, Nagy L, Dávid L, Vasa L, Balogh P. (2013): Technology planning system as a decision support tool for dairy farms in Hungary. Acta Polytechnica Hungarica, Vol. 10 Iss 8 pp. 231-244.

Guo Q, Jin B. (2009): Development of E-business and Networking in Rural Small and Medium-sized Enterprises. Information Science and Engineering (ICISE). Nanjing, China, pp. 2912-2915.

Hungarian Central Statistical Office (HCSO) databases

Kaloxylos A, Wolfert J, Verwaart T, Terol CM, Brewster C, Robbemond R, Sundmaker H. (2013): The Use of Future Internet Technologies in the Agriculture and Food Sectors: Integrating the Supply Chain. Procedia Technology, Vol. 8 pp. 51-60.

Kusumaningtyas N, Suwarto DH. (2015): ICT Adoption, Skill and Use Differences among Small and Medium Enterprises Managers Based on Demographic Factors. Procedia - Social and Behavioral Sciences, Vol. 169 pp. 296-302.

Martin FM, Ciovica L, Cristescu MP. (2013): Implication of Human Capital in the Development of SMEs through the ICT Adoption. Procedia Economics and Finance 6. pp. 748-753.

Matthews P. (2007): ICT assimilation and SME expansion. Journal of International Development, Vol. 19 Iss 6 pp. 817-827

OECD. (2015): OECD Digital Economy Outlook 2015. OECD Publishing, Paris, France.

Ongori H, Migiro SO. (2009): Information and communication technologies adoption in SMEs: literature review. Journal of Chinese Entrepreneurship, Vol. 2 Iss 1 pp. 93-104. Emerald Group Publishing Limited. Available at: www.emeraldinsight.com/1756-1396.htm

Pierson J. (2005): The take-up of ICT by micro-enterprises: An assessment of the bottlenecks and of European initiatives. Communication \& Strategies, Vol. 57 1st quarter. p.25.

Poppe KJ, Wolfert S, Verdouw C, Verwaart T. (2013): Information and Communication Technology as a Driver for Change in Agri-food Chains. EuroChoices, Vol. 12. Iss 1 pp. 60- 65.

Pullman M, Wu Z. (2012): Food Supply Chain Management - Economic, Social and Environmental Perspectives. Routledge, New York, USA.

Rahmana A. (2009): Peranan Teknologi Informasi dalam Peningkatan Daya Saing Industri Kecil Menengah. Seminar Nasional Aplikasi. Teknologi Informasi 2009

Ramírez-Medina, JA. (2009): Enterprise 2.0 Readiness Index. pp. 2677-2684. In: PICMET 2009 Proceedings, August 2-6, Portland, Oregon USA. IEEE ISBN 978-1-890843-20-5 Department of Engineering and Technology Management Portland State University, Maseeh College of Engineering \& Computer Science Portland, Oregon USA. August 2-6 2009

Sasvári P. (2016): The analysis of the knowledge and use of Cloud Computing among enterprises in Austria and Hungary. Gradius, Vol. 3 Iss 1 pp. 478-484.

Struzak R. (2010): Broadband Internet in EU Countries: Limits to Growth. IEEE Communication Magazine, Vol. 48 Iss 40 pp. 52-57.

Szira Z. (2014): The situaton of the SME sector in Hungary. In: Management, Enterprise and Benchmarking - In the 21st Century. Econpapers, Budapest, Hungary. pp. 107-118.

Taruté A, Gatautis R. (2014): ICT impact on SMEs performance. Procedia - Social and Behavorial Sciences, 110. pp. 1218-1225.

Wolfert S, Verdouw CN, Verloop CM, Beulens AJM. (2010): Organizing information integration in agri-food - A method based on a service-oriented architecture and living lab approach. Computers and Electronics in Agriculture, Vol. 70. pp. 389-405. 
